\title{
Myofibroblastic Differentiation
}

National Cancer Institute

\section{Source}

National Cancer Institute. Myofibroblastic Differentiation. NCI Thesaurus. Code C49101.

A morphologic finding that indicates the presence of myofibroblastic differentiation in a cellular infiltrate of a tissue sample. 